\title{
Ultrasound findings in pregnant women with uncomplicated vivax malaria in the Brazilian Amazon: a cohort study
}

\author{
Marianna F Brock ${ }^{1,2^{*}}$, Angélica E Miranda ${ }^{1,3}$, Camila Bôtto-Menezes ${ }^{1,2}$, Jorge RT Leão ${ }^{2}$
} and Flor E Martinez-Espinosa ${ }^{1,4}$

\begin{abstract}
Background: During pregnancy, Plasmodium falciparum-induced malaria can cause placental lesions and intrauterine growth restriction (IUGR). There are few published studies on Plasmodium vivax-induced malaria in pregnancy. Ultrasound is an efficient method for evaluating foetal biometry and placenta. The present study aimed to investigate the occurrence of increased placental thickness, foetal biometry and the amniotic fluid via ultrasound in a cohort of pregnant women with vivax malaria in Manaus, Amazonas, Brazil.

Methods: A cohort study was conducted among 118 pregnant women with vivax malaria and 191 pregnant women without malaria. Foetal biometry, placental thicknesses and the amniotic fluid were evaluated via ultrasound. Biometric data were distributed by the trimester in which the infection occurred and converted to $Z$ scores. The results were compared between the groups.

Results: Among pregnant women from the cohort, increased placental thickness was observed in ten women with malaria ( 8.5 vs $0 \% ; p<0.001$ ). The $Z$ scores of biometric parameters were not statistically significant when comparing the groups or according to the time of infection. In ultrasound results of the 118 pregnant women with malaria, seven (6\%) showed low foetal weight, two (1.7\%) showed oligohydramnios and one (0.85\%) showed foetal malformation. There was no significant difference when these variables were compared to those of the control group.

Conclusions: The placental thickness changes were significant but caused no foetal repercussions at birth. The ultrasound findings except placental thickness were similar in both groups, possibly because this is a low-endemic area and the pregnant women in the study were followed up in an active detection system that allowed early diagnosis and treatment of new malaria episodes.
\end{abstract}

Keywords: Malaria, Vivax, Ultrasonography, Pregnancy, Amazon, Placental thickness

\section{Background}

Malaria is among the most important public health issues worldwide [1]. In Latin America, it is estimated four in every 100 pregnancies are affected by malaria, and there is a high incidence in Brazil [2]. In 2011, 99.7\% of malarial transmission was concentrated within the Amazonian region [1-4], where malaria transmission

\footnotetext{
* Correspondence: mariannabrock@hotmail.com

'Fundação de Medicina Tropical Dr. Heitor Vieira Dourado, Av Pedro Teixeira 25, 69040-000 Manaus, Amazonas, Brasil

${ }^{2}$ Universidade do Estado do Amazonas, Av Castelo Branco 1777, Manaus,

Amazonas, Brasil

Full list of author information is available at the end of the article
}

is considered low and unstable and the most prevalent parasite species is Plasmodium vivax $[1,5,6]$.

Pregnant women are more susceptible than the general population to Plasmodium sp. infections [7], and malaria can convert normal pregnancies into pathological pregnancies [8-11]. During pregnancy, Plasmodium falciparum-induced malaria can cause placental lesions and changes in foetal oxygenation that lead to neonatal impairments, such as intrauterine growth restriction (IUGR), decreased amniotic fluid, prematurity and brain injuries caused by hypoxia and intrauterine death [12-14]. Studies in Thailand, India and Bolivia showed that compared to non-infected women, $P$. vivax-infected 
pregnant women are more often anaemic and have newborns with lower birth weights [3,15-17].

Ultrasound is a useful tool for detecting IUGR and determining the gestational age by foetal biometry [18]. Placental ultrasound can assess the placental thickness, texture and maturity level, and thus contributes to diagnoses of placental insufficiency $[19,20]$. Placental thickness has been associated with various maternal and foetal conditions, including infections (toxoplasmosis, rubella, cytomegalovirus, and other infections), diabetes, anaemia, and hydrops, while decreased placental thickness has been associated with pre-eclampsia, thyroid disease, placenta insufficiency and IUGR [21-23].

In cases of placental insufficiency and chronic hypoxia, the foetus adapts to the new situation by protecting its important organs. This mechanism leads to decreased diuresis and secretion of pulmonary fluids and subsequently leads to oligohydramnios, which is usually detected via ultrasound [24]

There is a lack of studies on ultrasound evaluations of foetal growth, amniotic fluid and placentas in pregnant women with vivax malaria. The present study aimed to investigate the occurrence of changes in placenta, foetal growth and amniotic fluid volumes by ultrasound in a cohort of pregnant women with vivax malaria in Manaus, Amazonas, Brazil.

\section{Methods}

A prospective cohort study of pregnant women with and without vivax malaria, all of whom had gold standard first trimester ultrasound dating scans (CRL $\leq 14 \mathrm{wks})$, were enrolled from January 2006 to July 2007 in the city of Manaus at the Dr Heitor Vieira Dourado Tropical Medicine Foundation (Fundação de Medicina Tropical Dr Heitor Vieira Dourado; FMT-HVD). This institution is also a primary care centre, diagnosing and treating patients with malaria even if they have no clinical complications. The unexposed group was selected from another close health unit devoted to antenatal care, attending patients with the same epidemiological profile in the same period, matched by maternal age and gestational age at inclusion.

The unexposed group was recruited in another clinic because the FMT-HVD is a reference hospital for infectious disease and infections in pregnancy were an excluding factor in these study (they can lead to IUGR and other diseases). The study design planned to include one unexposed woman for each exposed pregnant woman. Most of the population from Manaus is of mixed races, therefore, ethnic group was not specified. Routine blood examinations were performed in all of them. The same physician performed the ultrasound in both groups.

\section{Malaria diagnosis}

The microscopic diagnosis was performed by thick blood smear in all women. Maternal parasite load was estimated using a semi-quantitative method as recommended by the Brazilian Ministry of Health: 200-300 parasites per cu mm; 301-500 parasites/cu mm; 501-10,000 parasites/cu mm; $10,001-100,000$ parasites/cu $\mathrm{mm}$ and 100,000 or more parasites/cu mm.

Parasite densities with differential counting of asexual stages were estimated by experienced microscopists, by counting the number of parasites in 200 leukocytes in high magnification fields, and the number of leukocytes/cu mm.

The thick blood smear was performed at the moment of recruitment and monthly when the patient returned to antenatal evaluation.

\section{Study procedures}

The patients recruited for the study were interviewed and responded to a questionnaire regarding clinical and demographic data and were subsequently referred to ultrasound evaluation. The ultrasound examinations were performed at the time of the malaria diagnosis and at 30-day intervals until the delivery date. The examinations were performed with the GE Voluson Expert and GE P6 devices (GE Healthcare, Little Chalfont, Buckinghamshire, UK) by a single examiner who was certified in ultrasound examination by the Brazilian College of Radiology (Colégio Brasileiro de Radiologia) and the Brazilian Federation of Gynecology and Obstetrics (Federação Brasileira de Ginecologia e Obstetrícia) and in Foetal Medicine by the Brazilian Federation of Gynecology and Obstetrics.

\section{Ultrasound examination}

The patients were examined while in the supine position for bi-dimensional evaluations. They were instructed to relax the abdominal muscles and not to position the arms under the head or cross the legs in order to prevent muscle contracture. The gestational age was estimated from the crown-rump length (CRL) during first trimester ultrasounds, according to the technique reported by Grisolia et al. [25]. During the second and third trimesters, foetal biometry was based on the biparietal diameter (BPD), head circumference $(\mathrm{HC})$, abdominal circumference (AC), and femur length (FL) The BPD and $\mathrm{HC}$ were measured according to Campbell and Thoms [26]; the AC was measured according to Campbell and Wilkin [27]; and, the FL was measured according to Kurmanavicius [28]. From 18 to 24 weeks, a foetal morphological study was performed and, in addition to measuring the biometry based on the long bone evaluation as described above, the tibia, fibula, radius, ulna, foot, and cerebellum were also measured to evaluate the foetal morphology. The biometric parameters based on the BPD, $\mathrm{HC}, \mathrm{AC}, \mathrm{FL}$, and weight were measured according to the 
Hadlock table [29]. Three measurements were obtained for each parameter, and the means of the three values were calculated. The professional that performed the ultrasound knew to which group each pregnant woman belonged.

In an attempt to eliminate problems caused by variations in the measurements according to the gestational age, the $\mathrm{Z}$ score was used to compare the ultrasound results between the two groups. When the score was two standard deviations or more above or below the mean, it was considered altered.

The $\mathrm{Z}$ scores were evaluated for all parameters according to the following formula: $\mathrm{Z}=(\mathrm{X}-\mathrm{M}(\mathrm{GA})) / \mathrm{SD}(\mathrm{GA})$, where $\mathrm{X}$ is the measured value (BPD, FL, HC and $A C$ ), $\mathrm{M}(\mathrm{GA})$ is the mean of the approximate value for the evaluated gestational age according to the normality, and $\mathrm{SD}(\mathrm{GA})$ is the standard deviation of the mean for the gestational age according to the standard curve.

The amniotic fluid was evaluated according to the amniotic fluid index (AFI) proposed by Phelan et al. [30]. The placental thickness and location were evaluated at a perpendicular plan to placental axis at the point of insertion of the umbilical cord, according to Perroti [31]. The results of placental thickness were presented in millimetres. The ultrasound results were analysed with perinatal data and data from the unexposed group. It is important to take into account that after $>24$ weeks ultrasound scans are prone to high rates of error on the measurements, but by using a control group this limitation is minimized. In both groups the following perinatal data were evaluated: gestational age at birth, birth type, foetal weight at birth, presence of malformations, and maternal parity.

In the group of pregnant women with malaria, the treatment comprised the use of chloroquine $(1,500 \mathrm{mg}$ for three days and then weekly prophylaxis with $300 \mathrm{mg}$ of chloroquine for 12 weeks), according to the recommendation of the Brazilian Ministry of Health [32]. In patients diagnosed with anaemia, ferrous sulphate (200 mg, three times/day) and folic acid (5 mg/day) were also prescribed according to the recommendation of the Brazilian Ministry of Health [33].

In both groups, obstetric complications were treated at the local maternity hospitals in the region, according to proximity to the patient's house; the births also occurred at these hospitals. Approximately one month after delivery, the patients came back to another medical evaluation, and newborn data such as body weight, Apgar scores and the presence of complications were collected from the newborn cards that were filled out at the maternity hospitals.

\section{Definitions of variables}

Vivax malaria: presence of $P$. vivax on the microscopic thick film examination;

Maternal anaemia: haemoglobin lower than $11 \mathrm{mg} / \mathrm{dl}$;
Maternal weight: measured upon enrolment and at each antenatal consultation until childbirth. Mother's weight prior to pregnancy was based on antenatal dates. Weight gain was defined as the difference in maternal weight between the first and last weight measured at antenatal consultation;

Low ultrasound weight: weight less than the tenth percentile for the gestational age;

Low weight at birth: weight at birth less than the tenth percentile for the gestational age. (Newborns birth weight was measured immediately after birth as Ministry of Health recommendation) [34];

Pre-term babies: newborns with gestational age less than 37 weeks according to the first trimester ultrasound;

IUGR: foetuses at term with low weight (less than the tenth percentile according to gestational age proposed by Olsen [35];

Abortion: birth that occurred before 20 weeks of age; Congenital abnormality: an abnormality that was present on the ultrasound and diagnosed by the trained neonatal doctor during the newborn examination; Increased placental thickness: placenta above the 90th percentile for the gestational age [36].

\section{Inclusion and exclusion criteria}

Patients with pregnancy diagnoses that were confirmed by a quantitative beta human chorionic gonadotropin test or an abdominal or transvaginal obstetric ultrasound during the first trimester, and who agreed to participate by providing informed, signed consent were included in the analysis.

Patients with non-vivax malaria, a previous diagnosis of maternal disease or any other factors that could affect the foetal growth or morphology of the foetus, such as hypertension, auto-immune disease, other infection, multiple pregnancy and diabetes (diagnosed by fasting blood glucose and/or oral glucose tolerance test), were excluded from the study. Patients whose gestational age could not be evaluated correctly because they did not undergo a first trimester ultrasound and patients who did not attend the follow-up examinations were also excluded from the analysis.

\section{Statistical analysis}

The results were tabulated with Excel (Microsoft Corporation, Redmond, WA, USA) and analysed with Epi-Info for Windows, version 3.5.3 [37] The data were organized and presented in graphs and tables. The variables were descriptively analysed by calculating the absolute and relative frequencies. For the quantitative variables, the analysis was performed by observing the minimum and maximum values and calculating the means. For continuous quantitative data, the Student's $t$ test was used for normally 
distributed variables, while the Mann-Whitney U test was used for non-parametric data. Categorical data were compared with the Chi-square test and Fisher's exact test when appropriate.

\section{Ethics statement}

The patients were informed about their participation in the study, and their consent was obtained through informed consent terms that were signed by the patients or their legal guardians. The present study was approved by the Research Ethics Committee of the Fundação de Medicina Tropical Dr Heitor Vieira Dourado (FMT-HVD) under protocol number 0836-05.

\section{Results}

During the study period, 214 pregnant women with malaria and 289 without malaria were referred for ultrasound examination. Among the group of pregnant women with malaria, three were excluded because of multiple pregnancy, 50 because of concomitant diseases (hypertension, other infections during gestation, triploidy, and diabetes), 20 because of falciparum malaria and 23 due to loss to follow-up (total of patients submitted to analysis was 118). Among the group of pregnant women without malaria, six were excluded because of multiple pregnancy, 53 because of concomitant diseases (hypertension, other infections and diabetes), and 39 due to loss to follow-up (total of patients submitted to analysis was 191).

There were no significant differences between the groups regarding to the mean age, education, parity, haemoglobin levels, and maternal weight gain during pregnancy (Table 1). The mean weight gain during pregnancy was $11.7 \mathrm{~kg}$ for malaria group and $13.2 \mathrm{~kg}$ among the pregnant group without malaria. In the group of

Table 1 Characteristics of pregnant women included in the study population in Amazonas, Brazil

\begin{tabular}{|c|c|c|c|c|c|c|c|}
\hline & $\begin{array}{l}\text { Vivax malaria } \\
\mathrm{n}=118 \\
\mathrm{f}_{\mathrm{i}}\end{array}$ & $\%$ & Range & $\begin{array}{l}\text { No malaria } \\
n=191 \\
f_{i}\end{array}$ & $\%$ & Range & P-value \\
\hline Age, years & $24.2(+/-1.4)$ & - - & $14-39$ & $23.5(+/-1.9)$ & -— & $15-39$ & \\
\hline \multicolumn{8}{|l|}{ Education } \\
\hline $1-4$ years & 40 & $33.9 \%$ & & 60 & $31.4 \%$ & & 0.74 \\
\hline $5-8$ years & 45 & $38.1 \%$ & & 92 & $48.1 \%$ & & 0.10 \\
\hline $9+$ years & 33 & $28 \%$ & & 39 & $20.4 \%$ & & 0.16 \\
\hline \multicolumn{8}{|l|}{ Parity } \\
\hline Nuliparous & 38 & $32.2 \%$ & & 78 & $40.8 \%$ & & 0.16 \\
\hline Secundiparous & 28 & $23.7 \%$ & & 51 & $26.7 \%$ & & 0.65 \\
\hline Multiparous & 52 & $44.1 \%$ & & 62 & $32.5 \%$ & & 0.06 \\
\hline \multicolumn{8}{|l|}{ Ga at inclusion } \\
\hline 1st trimester & 13 & $11.0 \%$ & & 29 & $15.3 \%$ & & 0.34 \\
\hline 2nd trimester & 73 & $61.8 \%$ & & 112 & $58.6 \%$ & & 0.95 \\
\hline 3rd trimester & 32 & $27.2 \%$ & & 50 & $26.1 \%$ & & 0.92 \\
\hline \multicolumn{8}{|c|}{ Mean gestational age at inclusion (weeks) } \\
\hline 1st trimester & 9.2 & -—— & & 9.7 & -— - & & 0.15 \\
\hline 2nd trimester & 19.1 & -—— & & 16.9 & -—— & & 0.99 \\
\hline 3rd trimester & 31.1 & - - & & 31.4 & -一 & & 0.36 \\
\hline \multicolumn{8}{|l|}{$\mathrm{Hb}$ at inclusion } \\
\hline 1st trimester & 10.4 & - & $7.2-13.5$ & 11.1 & - & 7.7-13.8 & 0.38 \\
\hline 2nd trimester & 11.0 & - & 7.4-14.1 & 11.5 & - & $8.0-14.3$ & 0.48 \\
\hline 3rd trimester & 10.9 & - & $7.6-13.5$ & 11.3 & - & $8.5-14.1$ & 0.38 \\
\hline Weigh gain, kg & 11.7 & & $5.3-17.2$ & 13.2 & & $8.4-18.6$ & 0.36 \\
\hline \multicolumn{8}{|c|}{ Placental thickness (mm) } \\
\hline $2^{\text {nd }}$ trimester & $22.5 \mathrm{~mm}(+/-3.8 \mathrm{~mm})$ & - & - & $17.6 \mathrm{~mm}(+/-3.7 \mathrm{~mm})$ & - & - & 0,000 \\
\hline $3^{\text {rd }}$ trimester & $34.8 \mathrm{~mm}(+/-3.8 \mathrm{~mm})$ & - & - & 31.4 mm (+/- $3.9 \mathrm{~mm})$ & - & -—— & 0,000 \\
\hline
\end{tabular}

$\mathrm{Ga}$, gestational age; $\mathrm{Hb}$, haemoglobin.

$\mathrm{f}_{\mathrm{i}}=$ simple absolute frequency;

A italicized p-value indicates a statistical difference at a $5 \%$ significance level. 
pregnant women with vivax malaria, 81 (68.61\%) had the first episode of malaria in lifetime in this pregnancy. Parasite load ranged from 501-10,000 parasites/cu mm. Among the patients with malaria, 13 (11.0\%) were included during the first trimester of pregnancy, 73 (61.8\%) during the second trimester and 32 (27.2\%) during the third trimester (Table 1).

\section{Ultrasound findings}

Of the ultrasounds from the 118 pregnant women with malaria, seven (6\%) showed low foetal weights, two (1.7\%) showed oligohydramnios, and one (0.85\%) showed foetal malformation. There was no significant difference when these variables were compared to those of the control group. However, increased placental thickness (above placental thickness average table) was only observed in ten pregnant women with malaria with anterior and posterior placenta (8.5\%) ( $\mathrm{p}<0.001$; Table 2).

Among the patients with increased placental thickness, five patients had haemoglobin $(\mathrm{Hb})$ levels above $11 \mathrm{mg} /$ $\mathrm{dl}$ and above the malaria group $\mathrm{Hb}$ mean $(10.9 \mathrm{mg} / \mathrm{dl})$. This group had no cases of IUGR or low birth weight and only one patient had pre-term labour with 34 weeks. None of those patients with increased placental thickness had had oligohydramnios, lateral or fundal placenta. Data from increased placental thickness group are presented in Additional file 1.
Comparing increased placental thickness group with placental normal thickness group, there were no statistical differences between maternal age, parity, mean gestational age, $\mathrm{Hb}$ levels at presentation, maternal weight gain, $\mathrm{BPD}, \mathrm{CC}, \mathrm{AC} \mathrm{Z}$-score, birth weight and gestational age at delivery (Table 3 ).

Placental analysis revealed a statistically significant increase of thickness in patients with malaria than in the without malaria group ( $\mathrm{p}<0,01)$ (Figure 1).

\section{Effects of malaria on BPD, $\mathrm{HC}, \mathrm{AC}, \mathrm{FL}, \mathrm{HC} / \mathrm{AC}$ ratio, and foetal weight}

The ultrasound measurements of foetal growth (BPD, HC, $\mathrm{AC}$, and FL) in the pregnant women with and without malaria were compared to the fifth, $50^{\text {th }}$ and $95^{\text {th }}$ percentiles in the daily use tables, according to the proposal by Hadlock et al. [29]. In both groups, the distributions of the evaluated parameters were similar throughout all gestational ages.

The $\mathrm{Z}$ scores were compared according to the trimester in which the patients contracted malaria. The first ultrasonography after malaria diagnosis and the last ultrasonography before the birth were compared. When comparing the groups, no significant differences were found in the mean $\mathrm{Z}$ scores of the ultrasounds with regard to the trimester of infection $\mathrm{p}>0.05$ in all parameters (Additional file 2). When the $\mathrm{Z}$ score data for all

Table 2 Ultrasound findings during pregnancy in women included in the study

\begin{tabular}{|c|c|c|c|c|c|c|}
\hline & $\begin{array}{l}\text { Vivax malaria } \\
n=118 \\
f_{i}\end{array}$ & $\%$ & $\begin{array}{l}\text { No malaria } \\
n=191 \\
f_{i}\end{array}$ & $\%$ & $\mathbf{R R}$ & $\begin{array}{l}\mathrm{P} \text { - } \\
\text { value }\end{array}$ \\
\hline \multicolumn{7}{|l|}{ Low USG weight } \\
\hline Yes & 7 & $6 \%$ & 8 & $4.2 \%$ & $\begin{array}{l}1.41 \\
(0.52-3.80)\end{array}$ & 0.67 \\
\hline No & 111 & $94 \%$ & 183 & $95.8 \%$ & & \\
\hline Placental thickness & & & & & - & 0.0000 \\
\hline Yes & 10 & $8.5 \%$ & 0 & $0 \%$ & & \\
\hline No & 108 & $79.6 \%$ & 191 & $100 \%$ & & \\
\hline Oligohydramnious & & & & & & 0.68 \\
\hline Yes & 2 & $1.7 \%$ & 6 & $3 \%$ & $\begin{array}{l}0.53 \\
(0.11-2.62)\end{array}$ & \\
\hline No & 116 & $98.3 \%$ & 185 & $97 \%$ & & \\
\hline Foetal malformation & & & & & & 0.70 \\
\hline Yes & $1+$ & $0.8 \%$ & $1^{*}$ & $0.5 \%$ & $\begin{array}{l}1.61 \\
(0.10-25.6)\end{array}$ & \\
\hline No & 117 & $99.2 \%$ & 190 & $99.5 \%$ & & \\
\hline
\end{tabular}

USG, ultrasonography.

$f_{i}=$ simple absolute frequency; $R R=$ Relative risk; (Confidence level $-\mathrm{Cl}=95 \%$ ).

A italicized p-value indicates a statistical difference at a $5 \%$ significance level.

+ malformation - harelip *malformation - renal dysplasia. 
Table 3 Comparison between pregnant with and without increased placental thickness

\begin{tabular}{|c|c|c|c|c|c|}
\hline \multirow[t]{3}{*}{ Variable } & \multicolumn{3}{|c|}{ Normal placental thickness } & \multirow{3}{*}{$\begin{array}{l}\text { Increased } \\
\text { placental } \\
\text { thickness } \\
n=10\end{array}$} & \multirow[t]{3}{*}{$p$} \\
\hline & Malaria & No malaria $n=191$ & Total $^{\mathrm{a}}$ & & \\
\hline & $n=108$ & & $n=299$ & & \\
\hline Mean age & $24.4(+/-1.3)$ & $23.5(\mathrm{sd}+/-1.9)$ & 23.8 & $21.8(+/-5.3)$ & 0.13 \\
\hline Primigravida & 34 & 78 & 112 & 4 & - \\
\hline Gestational age (weeks) (mean) & $21.5(s d+/-1.8)$ & $19.5(\mathrm{sd}+/-1.3)$ & $20.2(s d+/-1.5)$ & $22.4(s d+/-2.5)$ & 0.40 \\
\hline Wt gain (kg) & $11.65(\mathrm{sd}+/-1.6)$ & $13.2(\mathrm{sd}+/-1.9)$ & 12.6 (sd: +/- 1.8) & $12.2(\mathrm{~s} / \mathrm{d}+/-1.25)$ & 0.67 \\
\hline $\mathrm{Hb}$ at presentation & $10.9(+/-0.9)$ & $11.3(+/-1.2)$ & $11.1(+/-1.0)$ & $10.5(+/-0.7)$ & 0.69 \\
\hline Avg parasite ${ }^{c}$ & $501-10,000$ & - & -———- & $501-10,000$ & - \\
\hline N episodes & 1.5 & -—— & -二-—-— & 1.6 & - \\
\hline Gest age 1st infection (weeks) & 21.5 & -— & -—- & 22.4 & 0.17 \\
\hline Z score DBP & 0.97 & 0.96 & 0.96 & 0.29 & 0.26 \\
\hline Z score CC & 0.02 & 0.03 & 0.02 & -0.11 & 0.66 \\
\hline Z score CA & 0.22 & 0.28 & 0.25 & 0.17 & 0.76 \\
\hline Z score F & 0.03 & 0.04 & 0.03 & 0.02 & 0.89 \\
\hline Z score placenta & 0.75 & -0.26 & 0.10 & 1.70 & 0.000 \\
\hline Birth weight $(\mathrm{kg})^{\mathrm{d}}$ & $3.158(s d+/-465)$ & $3.277(s d+/-472.5)$ & $3.234(\mathrm{sd}+/-468 \mathrm{~g})$ & $3.383(\mathrm{sd}+/-469 \mathrm{~g})$ & 0.75 \\
\hline GA at delivery (weeks) & $38.5(+/-2,2)$ & $38.7(+/-2,6)$ & $38.6(+/-2,4)$ & $38.8(+/-2,2)$ & 0.77 \\
\hline
\end{tabular}

${ }^{a}$ All comparisons were made between the groups: increased placental thickness and total of normal placental thickness (malaria normal thickness + no malaria group); ${ }^{\mathrm{b}}$ All patients had malaria.

cparasites per cu mm;

${ }^{\mathrm{d}}$ Birth weight in grams.

A italicized p-value indicates a statistical difference at a $5 \%$ significance level.

trimesters were pooled, there were no significant difference $(\mathrm{p}>0.05)$.

To evaluate the effect of the malaria exposure time on foetal changes, survival curves were constructed to analyse the exposure time (in the group with malaria) or the inclusion in the study (group without malaria) with respect to impairment in the foetal weight, BPD, $\mathrm{HC}$, $\mathrm{FL}$, or AC. No significant impairments were found between the groups and the exposure time (Figure 2). An analysis with the same parameters according to the trimester of infection was also performed and did not reveal any significant differences.

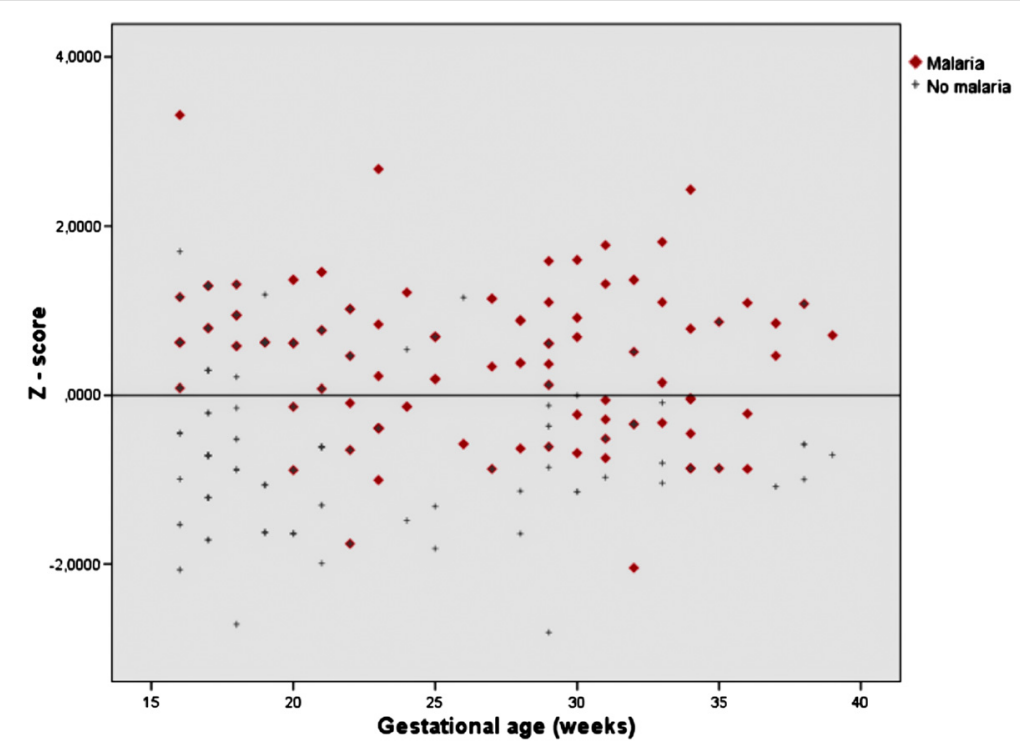

Figure 1 Relation between placental thickness z-score and gestational age in malaria group (red rhombus) and no malaria group (grey cross). 

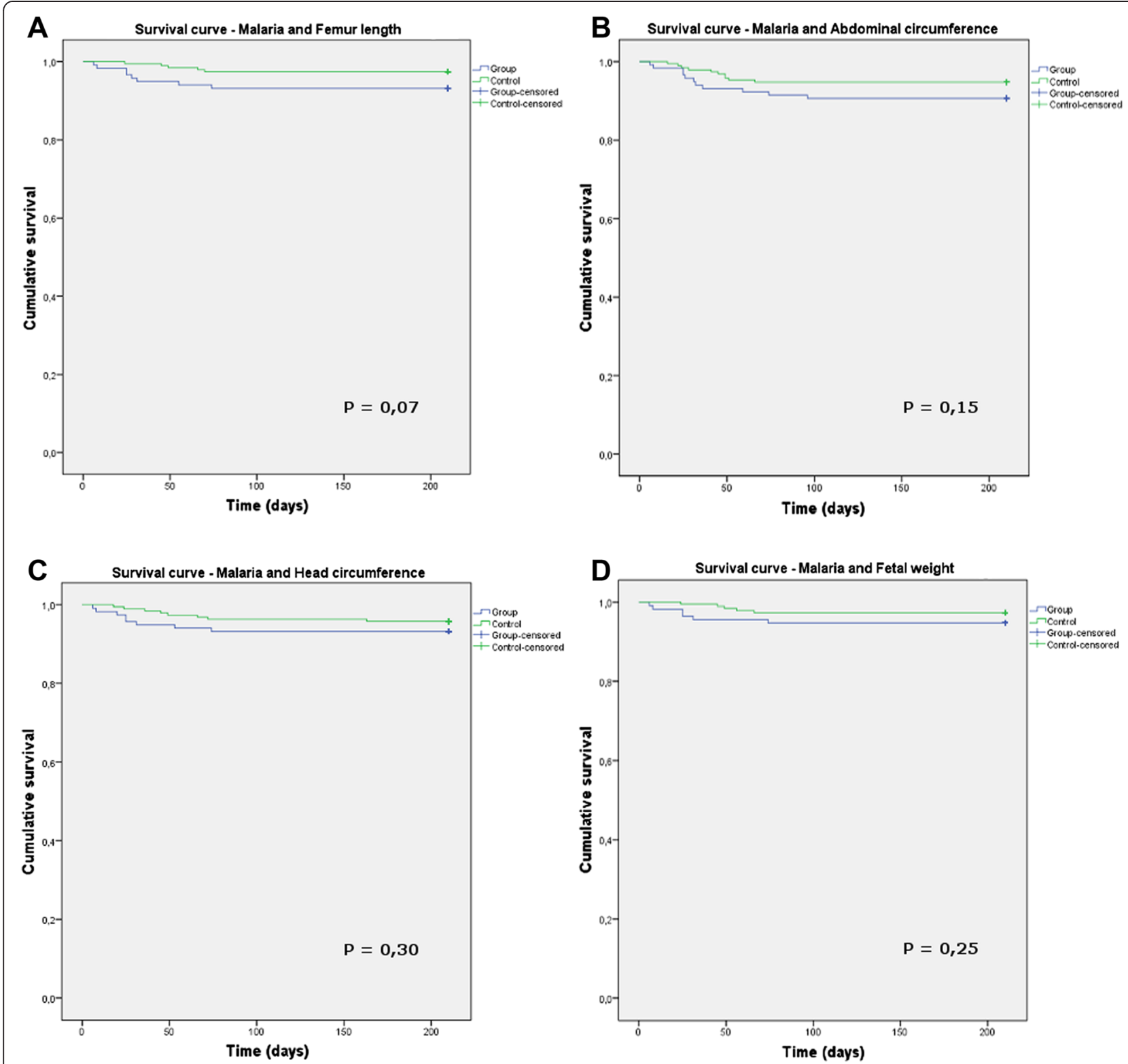

Figure 2 Survival curves to compare the time of exposure to the occurrence of impairment. A: malaria vs femur length; B: malaria vs abdominal circumference; C: malaria vs head circumference (HC); D: malaria vs foetal weight. In all graphs: malaria group, blue line; control group, green line. Cumulative survival was defined as the percentage of foetuses that did not have a measurement $<2$ SD.

\section{Malaria and perinatal results}

Table 4 shows the perinatal results. There were no significant differences between the malaria-exposed and unexposed groups with regard to the perinatal results.

\section{Pregnant women with malaria}

Among the 118 pregnant women with vivax malaria, 109 (92.4\%) initiated treatment on the day of symptom onset. The other nine initiated treatment up to five days after symptom onset. All initiated treatment on the same day of diagnosis of vivax malaria by the thick blood film.
Comparing the mean $\mathrm{Hb}$ levels with increased placental thickness, low birth weight or pre-term births there were no significant difference between the groups of pregnant women with lower $\mathrm{Hb}$ levels and increased placental thickness (Table 5).

The time to the first ultrasound examination ranged from 0-15 days after the diagnosis of the symptoms, with a mean of five days. Sixteen patients evolved with relapse throughout the follow-up period, however these patients did not present any ultrasound differences as compared to those that did not relapse. 
Table 4 Included foetal/newborn data from the study population in Amazonas, Brazil

\begin{tabular}{|c|c|c|c|c|c|c|c|c|}
\hline & $\begin{array}{l}\text { Vivax malaria } \\
n=118 \\
f_{i}\end{array}$ & $\%$ & Range & $\begin{array}{l}\text { Malaria } \\
\text { negative } \\
n=191 \\
f_{i}\end{array}$ & $\%$ & Range & RR & $p$-value \\
\hline \multicolumn{9}{|l|}{ Foetal gender } \\
\hline Male & 64 & $54.3 \%$ & & 102 & $53.5 \%$ & & -—-二- & 0.97 \\
\hline Female & 54 & $45.7 \%$ & & 89 & $46.5 \%$ & & -二-二- & 0.64 \\
\hline Birth weight & $3,177 \mathrm{~g}(+/-482.5 \mathrm{~g})$ & & $1,945-4,715 \mathrm{~g}$ & $3,277 \mathrm{~g}(+/-472.5 \mathrm{~g})$ & & $590-4,290 \mathrm{~g}$ & -————- & 0.33 \\
\hline LBW yes & 7 & $5.9 \%$ & & 18 & $9.5 \%$ & & $0.71(0.37-1.36)$ & 0.37 \\
\hline LBW no & 111 & $94.1 \%$ & & 173 & $90.5 \%$ & & & \\
\hline Malformation & 1 & $0.8 \%$ & & 1 & $0.8 \%$ & & $1.31(0.32-5.28)$ & 0.14 \\
\hline Pre-term delivery & 19 & $16 \%$ & & 19 & $9.9 \%$ & & & 0.16 \\
\hline
\end{tabular}

LBW, low birth weight; $f_{i}=$ simple absolute frequency; $R R=$ Relative risk; (Confidence level $\left.-\mathrm{Cl}=95 \%\right)$.

\section{Discussion}

The present study evaluates foetal and placental ultrasound changes in pregnant women with vivax malaria in Latin America. Significant differences in the placental thicknesses between the malaria and non-malaria groups were revealed via placental ultrasound. Ultrasound studies of placental thickness have reported that placentas with increased thicknesses are more likely to be associated with hydrops, molar pregnancy, other infections during pregnancy, triploidy, maternal diabetes mellitus, anaemia and aneuploidy $[36,38]$.

Increased placental thickness does not comprise a specific diagnosis of any disease. However, it can act as an

Table 5 Comparison of haemoglobin levels relative to the ultrasound findings throughout the pregnancy

\begin{tabular}{|c|c|c|c|c|c|c|}
\hline \multirow{3}{*}{ Variables } & \multicolumn{4}{|c|}{ Haemoglobin (mg/dL) } & \multirow[b]{3}{*}{ Total } & \multirow[b]{3}{*}{ 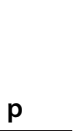 } \\
\hline & \multicolumn{2}{|c|}{$<10.9$} & \multicolumn{2}{|c|}{$\geq 10.9$} & & \\
\hline & $f_{i}$ & $\%$ & $f_{i}$ & $\%$ & & \\
\hline \multicolumn{7}{|c|}{ Placental thickness $(n=118)$} \\
\hline Yes & 5 & 50 & 5 & 50 & 10 & 0,381 \\
\hline No & 47 & 43.5 & 61 & 56.5 & 108 & \\
\hline USG $(n=118)$ & & & & & & 0.117 \\
\hline Abnormal findings & 23 & 42.2 & 37 & 57.8 & 60 & \\
\hline Normal & 29 & 50 & 29 & 50 & 58 & \\
\hline LBW $(n=118)$ & & & & & & 0.744 \\
\hline Yes & 3 & 42.8 & 4 & 57.2 & 7 & \\
\hline No & 49 & 44.2 & 62 & 55.8 & 111 & \\
\hline PTL $(n=118)$ & & & & & & 0.883 \\
\hline Yes & 8 & 44.5 & 10 & 55.5 & 18 & \\
\hline No & 44 & 44.0 & 56 & 56.0 & 100 & \\
\hline
\end{tabular}

USG, ultrasonography; LBW, low birth weight, PTL, pre-term labour. $f_{i}=$ simple absolute frequency. alert to identify foetuses at high risk of disease resulting in inflammation, oedema or compensatory hypertrophy [36].

Lee et al. [21-23] studying placental thickness in the second trimester found that placental position could lead to an increased placental thickness. Despite that placental thickness may vary with the implantation site, there were no case of fundal or lateral placenta in the increased placental thickness group that would influence placental thickness.

Godfrey et al. [39] in their study of the effect of maternal anaemia and iron deficiency on the ratio of foetal weight to placental weight, Agboola [40] studying the effect of type and duration of anaemia on placental weight and villous anaemia, Baptiste-Roberts et al. [41] studying maternal risk factors for abnormal placental growth, found that increased placental thickness could be result in foetal hypoxaemia consequent to anaemia stimulating growth to impaired oxygen transportation [39]. There was no significant correlation between the pregnant women with regard to anaemia and increased placental thickness, and patients with diseases such as diabetes or infections were excluded from the present study, strengthening the hypothesis that increased placental thickness resulted from inflammation or oedema.

When using three-dimensional ultrasound to study placental volumes in pregnant women with vivax and falciparum malaria in Thailand, Rijken et al. [42] found no significant differences between the placental volumes of the pregnant women with vivax malaria and those without malaria [42]. No studies have been conducted on measurements of placental thickness in pregnant women with malaria, and the existing studies on vivax malaria and placentas address histopathology and do not seem to demonstrate that $P$. vivax causes inflammation in the intervillous spaces $[43,44]$.

In a study of the effects of placental $P$. falciparum and $P$. vivax infections on placental histopathology in low 
malaria transmission areas, McGready et al. [45] found histopathological changes in a small proportion of the placentas from $P$. falciparum-infected patients, especially those who were infected soon before delivery. The $P$. vivax infections in this study by McGready et al. [45] were associated only with the presence of a malarial pigment in some placentas, indicating that prompt and adequate parasitaemia treatment during gestation would limit placental disease, emphasizing the importance of treating the infection with anti-malarial drugs during gestation [45]. Studies that correlate the placental thickness on ultrasound with histopathology should be performed to define the cause of the increased placental thickness observed in the present study.

The foetal biometry measurements, including BPD, FL, $\mathrm{AC}$, and foetal weight, are important tools with which to evaluate gestational age, IUGR and detecting obstetrics problems. It is fundamental to know the correct gestational age measured by a first trimester ultrasonography and compare the foetal biometry and the weight expected for the gestational age, as was done in this study [46-48].

In the present study, most of the pregnant women developed malaria during the second and third trimesters of gestation, and an asymmetric growth restriction with an abdominal circumference reduction was expected, but not observed. In both groups, the weights were similar to those considered adequate in the $50^{\text {th }}$ percentile for the 38- to 40-week age range, according to a study by Pedreira et al. on gestational age-based foetal weight parameters in Brazil [49].

Some studies showed that recently infected women supposedly have a tendency towards more favourable perinatal outcomes because of the absence of immunological memory $[7,50,51]$. In the present study, most of the patients were recently infected, and there was no association between recent infection and ultrasound or neonatal changes. Given their existing lower physiological immunity, non-immune pregnant women would supposedly have a tendency towards a higher susceptibility to malaria and more severe conditions with recent infections, which was not observed [6,51].

In a study of foetal biometry via umbilical artery and uterine artery Doppler in women with vivax malaria in Msambweni, Dent et al. concluded that earlier treatment yielded fewer or even no effects throughout the gestation [52]. Rikjen, studying ultrasound evidence of early foetal growth restriction after maternal malaria infection, found that intermittent preventive treatments are the main strategy to prevent malaria, reduce anaemia and low birth weight [53]. Schmiegelow, studying malaria and foetal growth alterations in the third trimester of pregnancy, concluded that the effects on foetal growth often occurred after a considerable delay in women who were diagnosed with malaria at the first antenatal visit and who subsequently strictly followed the antenatal programme and the recommended measures to prevent malaria infections [54]. Thus, active malaria screening must be encouraged in pregnant women to ensure the early implementation of treatment and obtain a low morbidity rate and good perinatal outcomes.

The antenatal supplementation with daily iron is effective in reducing the risk of low birth weight $[55,56]$. This could also explain the lack of differences between the two groups at the end of follow-up, as evidence of the benefit of this supplementation, however this finding needs further study in endemic areas, such as those in Latin America. Another possible determinant of the lack of major differences between the two groups was that women initiated treatment very early, due to their easy access to the health system in Manaus and surrounding areas. This probably reinforces the impact of early diagnosis in endemic areas to this population.

It is worth noting that no changes in the demographic data were observed among the groups of pregnant women, suggesting that the groups were homogeneous and that epidemiological factors were not confounding factors in this study.

In the present study, the changes in the placental thickness, although significant, did not cause foetal repercussions at birth. There were no morphological or foetal changes that could be considered characteristic of foetal involvement in vivax malaria. The fact that the ultrasound examinations agreed with those from a cohort group of unexposed pregnant women was most likely due to the area being of low endemicity, and therefore, all pregnant women in the present study participated in follow-ups in an active detection system that allowed early diagnosis and treatment of new malarial episodes. The treatment and control of infections and relapses ensured that the behaviour of the infected group was similar to that of the group of pregnant women without malaria. In these study, malaria was an acute and non-chronic event with acute consequences that, in most cases, did not have any consequences and retreated spontaneously after treatment, thus demonstrating the benefits of adequate treatment and close follow-up of infected cases. All women were treated with chloroquine, and recent data showed that $P$. vivax chloroquineresistance is supposed to be around 5\% [57].

Limitations of the present study were low power of the study in order to estimate the frequency of low birth weight in P. vivax infection; only thick blood smears were performed; PCR to diagnose low parasitaemia could not be performed; patients performed weekly prophylaxis with chloroquine without supervision; some infections such as syphilis, toxoplasmosis and rubella were excluded because are routinely tested in antenatal care, but other infections, although rare, were not 
excluded and could have lead to increased placental thickness; the examinations were performed by an ultrasound examiner who was not blinded to the presence or absence of infection, leading to bias. Furthermore, variables derived from ultrasound biometry followed the Hadlock reference table from a North American population, impairing a precise estimation in the Amazonian population. However, using a control group this limitation was surpassed.

\section{Conclusions}

The placental thickness changes were significant but caused no foetal repercussions at birth. The ultrasound findings except placental thickness were similar in both groups, possibly because this is a low-endemic area and the pregnant women in the study were followed up in an active detection system that allowed early diagnosis and treatment of new malaria episodes.

From the public health perspective, the finding of increased placental thickness could be a sentinel marker of malarial infection and this information could be useful for those who perform ultrasound examinations in remote areas, alerting the need of thick blood smear systematically. However, further studies in other areas are needed to confirm this finding.

\section{Additional files}

\section{Additional file 1: Characteristics of the pregnant women with placental thickness.}

Additional file 2: Comparison of the study groups with regard to the $\mathrm{Z}$ scores of the BPD, $\mathrm{HC}, \mathrm{AC}$, and $\mathrm{FL}$ of the pregnant women according to the trimester of recruitment.

\section{Competing interests}

The authors declare that they have no competing interests.

\section{Authors' contributions}

MFB and FEME: experimental concept and design; FEME and CB cared for/ treated patients in the outpatient clinic; MFB: ultrasound scan performance; MFB, JRL and AEM: data analysis; MFB and AME: manuscript writing; MFB, $A E M, C B$, JRL, FEME: critical reading and review of the manuscript. All authors read and approved the final manuscript.

\section{Acknowledgements}

We would like to thank our study participants and the health staff of the FMT-HVD and maternity for their contributions for the study.

\section{Disclaimer}

This study was presented as part of the doctoral degree thesis of MB for the Tropical Medicine Post-Graduate Programme at Amazonas State University/ Dr Heitor Vieira Dourado Tropical Medicine Foundation.

\section{Author details}

${ }^{1}$ Fundação de Medicina Tropical Dr. Heitor Vieira Dourado, Av Pedro Teixeira 25, 69040-000 Manaus, Amazonas, Brasil. ²Universidade do Estado do Amazonas, Av Castelo Branco 1777, Manaus, Amazonas, Brasil. ${ }^{3}$ Universidade Federal do Espírito Santo, Vitória, Espirito Santo, Brasil. ${ }^{4}$ Instituto Leônidas e Maria Deane, FIOCRUZ Amazonas, R Terezina 476, 69057070 Manaus, Amazonas, Brasil.
Received: 21 August 2014 Accepted: 1 March 2015

Published online: 08 April 2015

\section{References}

1. WHO. World Malaria Report. Geneva, Switzerland, World Health Organization, 2012:238. http://www.who.int/malaria/publications/ world_malaria_report_2012/en/

2. Jacinto SO, Silva, K, Pamplona MS. Gestação de alto risco: manual técnico. 5th edition. Brasília - Brasil: MInistério da Saúde; 2010. http://bvsms.saude. gov.br/bvs/publicacoes/gestacao_alto_risco.pdf

3. Brutus L, Santalla J, Schneider D, Avila JC, Deloron P. Plasmodium vivax malaria during pregnancy, Bolivia. Emerg Infect Dis. 2013;19:1605-11.

4. Ministério da Saúde (Brasil) SVS. Situação Epidemiológica da Malária no Brasil, 2010 a 2011. Boletim Epidemiológico da Malária - 2013. 2013, 44:1-16. http:// bvsms.saude.gov.br/bvs/periodicos/boletim_epidemiologico_numero_1_2013.pdf

5. Oliveira-Ferreira J, Lacerda MV, Brasil P, Ladislau JL, Tauil PL, Daniel-Ribeiro CT. Malaria in Brazil: an overview. Malar J. 2010;9:115.

6. Chagas EC, Do Nascimento CT, De Santana Filho FS, Botto-Menezes CH, Martinez-Espinosa FE. Impact of malaria during pregnancy in the Amazon region. Rev Panam Salud Publica. 2009;26:203-8.

7. Martinez-Espinosa FE, Daniel-Ribeiro $C$, Alecrim WD. Malaria during pregnancy in a reference centre from the Brazilian Amazon: unexpected increase in the frequency of Plasmodium falciparum infections. Mem Inst Oswaldo Cruz. 2004;99:19-21.

8. Brabin B, Piper C. Anaemia- and malaria-attributable low birthweight in two populations in Papua New Guinea. Ann Hum Biol. 1997;24:547-55.

9. Kasumba IN, Nalunkuma AJ, Mujuzi G, Kitaka FS, Byaruhanga R, Okong P, et al. Low birthweight associated with maternal anaemia and Plasmodium falciparum infection during pregnancy, in a peri-urban/urban area of low endemicity in Uganda. Ann Trop Med Parasitol. 2000;94:7-13.

10. Brabin BJ, Romagosa C, Abdelgalil S, Menendez C, Verhoeff FH, McGready R, et al. The sick placenta-the role of malaria. Placenta. 2004;25:359-78.

11. Umbers AJ, Aitken EH, Rogerson SJ. Malaria in pregnancy: small babies, big problem. Trends Parasitol. 2011;27:168-75.

12. Takem EN, D'Alessandro U. Malaria in pregnancy. Mediterr J Hematol Infect Dis. 2013;5:e2013010.

13. Tongo $\mathrm{OO}$, Orimadegun $\mathrm{AE}$, Akinyinka $\mathrm{OO}$. Utilisation of malaria preventive measures during pregnancy and birth outcomes in Ibadan. Nigeria BMC Pregnancy Childbirth. 2011;11:60.

14. Nayak KC, Khatri MP, Gupta BK, Sirohi P, Choudhary V, Verma SK, et al. Spectrum of vivax malaria in pregnancy and its outcome: a hospital-based study. J Vector Borne Dis. 2009;46:299-302.

15. Nosten F, McGready R, Simpson JA, Thwai KL, Balkan S, Cho T, et al. Effects of Plasmodium vivax malaria in pregnancy. Lancet. 1999;354:546-9.

16. Nosten F, Rogerson SJ, Beeson JG, McGready R, Mutabingwa TK, Brabin B. Malaria in pregnancy and the endemicity spectrum: what can we learn? Trends Parasitol. 2004;20:425-32.

17. Singh N, Shukla MM, Sharma VP. Epidemiology of malaria in pregnancy in central India. Bull World Health Organ. 1999;77:567-72.

18. Degani S. Fetal biometry: clinical, pathological, and technical considerations. Obstet Gynecol Surv. 2001;56:159-67.

19. Hoddick WK, Mahony BS, Callen PW, Filly RA. Placental thickness. J Ultrasound Med. 1985:4:479-82.

20. ljaiya MA, Aboyeji AP, Braimoh KT, Abubakar D. The role of ultrasound in obstetrics. Niger J Med. 2002;11:50-5.

21. Mathai BM, Singla SC, Nittala PP, Chakravarti RJ, Toppo JN. Placental thickness: its correlation with ultrasonographic gestational age in normal and intrauterine growth-retarded pregnancies in the late second and third trimester. J Obstet Gynaecol India. 2013;63:230-3.

22. Afrakhteh M, Moeini A, Taheri MS, Haghighatkhah HR. Correlation between placental thickness in the second and third trimester and fetal weight. Rev Bras Ginecol Obstet. 2013;35:317-22.

23. Lee AJ, Bethune M, Hiscock RJ. Placental thickness in the second trimester: a pilot study to determine the normal range. J Ultrasound Med. 2012;31:213-8.

24. Velho MTC, Morais EN, Ethur ABM. Determinação ultra-sonográfica do líquido amniótico em grávidas normias, da $12^{\mathrm{a}}$ à $42^{\mathrm{a}}$ semana de gravidez. Rev Bras Ginecol Obstet. 2001;23:225-32.

25. Grisolia G, Milano K, Pilu G, Banzi C, David C, Gabrielli S, et al. Biometry of early pregnancy with transvaginal sonography. Ultrasound Obstet Gynecol. 1993;3:403-11. 
26. Campbell S, Thoms A. Ultrasound measurement of the fetal head to abdomen circumference ratio in the assessment of growth retardation. Br J Obstet Gynaecol. 1977:84:165-74.

27. Campbell S, Wilkin D. Ultrasonic measurement of fetal abdomen circumference in the estimation of fetal weight. Br J Obstet Gynaecol. 1975;82:689-97.

28. Kurmanavicius J, Wright EM, Royston P, Wisser J, Huch R, Huch A, et al. Fetal ultrasound biometry: 1. Head reference values. $\mathrm{Br} J$ Obstet Gynaecol. 1999;106:126-35.

29. Hadlock FP, Harrist RB, Sharman RS, Deter RL, Park SK. Estimation of fetal weight with the use of head, body, and femur measurements-a prospective study. Am J Obstet Gynecol. 1985;151:333-7.

30. Phelan JP, Ahn MO, Smith CV, Rutherford SE, Anderson E. Amniotic fluid index measurements during pregnancy. J Reprod Med. 1987;32:601-4.

31. Perroti MR. Evolução das características ecográficas da placenta, da posição e da apresentação fetal em gestações normais. Rev Bras Ginecol Obstet. 1999:21:100-10.

32. Fontes CIF SA, da Silva CM, Tauil PL, Landislau JLB. Malaria treatment in Brazil - practical guide. Brasilia: Ministerio da Saúde, Secretaria de vigilância em saúde; 2010. ftp://ftp.cve. saude.sp.gov.br/doc_tec/zoo/malaria10_guia_tratamento.pdf

33. Ministério da Saúde Secretaria de Atenção à Saúde Departamento de Ações Programáticas Estratégicas Brasil. Gestação de alto risco: manual técnico. 5th edn. Brasília, Brasil: MInistério da Saúde; 2010. http://bvsms.saude.gov.br/ bvs/publicacoes/manual tecnico_gestacao_alto risco.pdf

34. Ministério da Saúde. Atenção à saúde do recém-nascido: guia para os profissionais de saúde. vol. 1. pp. 148. Brasil: Ministério da Saúde; 2011. http://www.redeblh.fiocruz.br/media/arn_v1.pdf

35. Olsen IE, Groveman SA, Lawson ML, Clark RH, Zemel BS. New intraterine growth curves based on United States data. Pediatrics. 2010;125:e214-24.

36. Elchalal U, Ezra Y, Levi Y, Bar-Oz B, Yanai N, Intrator O, et al. Sonographically thick placenta: a marker for increased perinatal risk-a prospective cross-sectional study. Placenta. 2000;21:268-72.

37. Centers for Desease Control and Prevention. Epi info. https://wwwn.cdc. gov/epiinfo/html/downloads.htm. (Acessed 16 mar 2015).

38. Ozcan T, Pressman EK. Imaging of the placenta. Ultrasound Clinics. 2008;3:13-22.

39. Godfrey KM, Redman CW, Barker DJ, Osmond C. The effect of maternal anaemia and iron deficiency on the ratio of fetal weight to placental weight. Br J Obstet Gynaecol. 2005;98:886-91.

40. Agboola A. Effect of type and duration of anemia on placental weight and villous histology. J Natl Med Assoc. 1979;71:1067-9.

41. Baptiste-Roberts K, Salafia CM, Nicholson WK, Duggan A, Wang NY, Brancati FL. Maternal risk factors for abnormal placental growth: the national collaborative perinatal project. BMC Pregnancy Childbirth. 2008;8:44

42. Rijken MJ, Moroski WE, Kiricharoen S, Karunkonkowit N, Stevenson G, Ohuma EO, et al. Effect of malaria on placental volume measured using three-dimensional ultrasound: a pilot study. Malar J. 2012;11:5

43. Souza RM, Ataide R, Dombrowski JG, Ippolito V, Aitken EH, Valle SN, et al Placental histopathological changes associated with Plasmodium vivax infection during pregnancy. PLoS Negl Trop Dis. 2013;7:e2071.

44. Mayor A, Bardaji A, Felger I, King CL, Cistero P, Dobano C, et al. Placental infection with Plasmodium vivax: a histopathological and molecular study. J Infect Dis. 2012;206:1904-10.

45. McGready R, Davison BB, Stepniewska K, Cho T, Shee H, Brockman A, et al. The effects of Plasmodium falciparum and $P$. vivax infections on placental histopathology in an area of low malaria transmission. Am J Trop Med Hyg. 2004;70:398-407.

46. Rijken MJ, Lee SJ, Boel ME, Papageorghiou AT, Visser GH, Dwell SL, et al. Obstetric ultrasound scanning by local health workers in a refugee camp on the Thai-Burmese border. Ultrasound Obstet Gynecol. 2009;34:395-403.

47. Rijken MJ, Rijken JA, Papageorghiou AT, Kennedy SH, Visser GH, Nosten F, et al. Malaria in pregnancy: the difficulties in measuring birthweight. $\mathrm{Br} J$ Obstet Gynaecol. 2011;118:671-8.

48. Rijken MJ, Mulder EJ, Papageorghiou AT, Thiptharakun S, Wah N, Paw TK, et al. Quality of ultrasound biometry obtained by local health workers in a refugee camp on the Thai-Burmese border. Ultrasound Obstet Gynecol. 2012:40:151-7.

49. Pedreira CE, Pinto FA, Pereira SP, Costa ES. Birth weight patterns by gestational age in Brazil. An Acad Bras Cienc. 2011;83:619-25.

50. Rodriguez-Morales AJ, Sanchez E, Vargas M, Piccolo C, Colina R, Arria M, et al. Pregnancy outcomes associated with Plasmodium vivax malaria in northeastern Venezuela. Am J Trop Med Hyg. 2006;74:755-7.
51. Menendez C. Malaria during pregnancy: a priority area of malaria research and control. Parasitol Today. 1995;11:178-83.

52. Dent A, Lazembnik N, Gisemba E, Kalayjian E, Bohinic L, King C. Fetal biometrics, umbilical and uterine Doppler studies among malaria infected and not infected pregnant women. Ultrasound Obstetrics Gynecol. 2011;38:130.

53. Rijken MJ, Papageorghiou AT, Thiptharakun S, Kiricharoen S, Dwell SL, Wiladphaingern $\mathrm{J}$, et al. Ultrasound evidence of early fetal growth restriction after maternal malaria infection. PLoS One. 2012;7:e31411.

54. Schmiegelow C, Minja D, Oesterholt M, Pehrson C, Suhrs HE, Bostrom S, et al. Malaria and fetal growth alterations in the 3rd trimester of pregnancy: a longitudinal ultrasound study. PLoS One. 2013;8:e53794.

55. Haider BA, Olofin I, Wang M, Spiegelman D, Ezzati M, Fawzi WW. Anaemia, prenatal iron use, and risk of adverse pregnancy outcomes: systematic review and meta-analysis. BMJ. 2013;346:f3443.

56. Pena-Rosas JP, De-Regil LM, Dowswell T, Viteri FE. Daily oral iron supplementation during pregnancy. Cochrane Database Syst Rev. 2012;12:CD004736.

57. Marques MM, Costa MR, Santana Filho FS, Vieira JL, Nascimento MT, Brasil LW, et al. Plasmodium vivax chloroquine resistance and anemia in the western Brazilian Amazon. Antimicrob Agents Chemother. 2014;58:342-7.

\section{Submit your next manuscript to BioMed Central and take full advantage of:}

- Convenient online submission

- Thorough peer review

- No space constraints or color figure charges

- Immediate publication on acceptance

- Inclusion in PubMed, CAS, Scopus and Google Scholar

- Research which is freely available for redistribution 